\title{
How neurons generate behavior in a hatchling amphibian tadpole: an outline
}

\author{
Alan Roberts ${ }^{1}$, Wen-Chang Li $^{2}$ and Steve R. Soffe \\ School of Biological Sciences, University of Bristol, Bristol, UK \\ 2 School of Biology, University of St Andrews, St Andrews, Scotland, UK
}

Edited by:

Paul S. Katz, Georgia State University,

USA

Reviewed by:

Mark Masino, University of Minnesota, USA

David McLean, Northwestern

University, USA

${ }^{*}$ Correspondence:

Alan Roberts, School of Biological

Sciences, University of Bristol, Bristol

BS8 1UG, UK.

e-mail:a.roberts@bristol.ac.uk
Adult nervous systems are so complex that understanding how they produce behavior remains a real challenge. We chose to study hatchling Xenopus tadpoles where behavior is controlled by a few thousand neurons but there is a very limited number of types of neuron. Young tadpoles can flex, swim away, adjust their trajectory, speed-up and slow-down, stop when they contact support and struggle when grasped. They are sensitive to touch, pressure, noxious stimuli, light intensity and water currents. Using whole-cell recording has led to rapid progress in understanding central networks controlling behavior. Our methods are illustrated by an analysis of the flexion reflex to skin touch. We then define the seven types of neuron that allow the tadpole to swim when the skin is touched and use paired recordings to investigate neuron properties, synaptic connections and activity patterns. Proposals on how the swim network operates are evaluated by experiment and network modeling. We then examine GABAergic inhibitory pathways that control swimming but also produce tonic inhibition to reduce responsiveness when the tadpole is at rest. Finally, we analyze the strong alternating struggling movements the tadpole makes when grasped. We show that the mechanisms for rhythm generation here are very different to those during swimming. Although much remains to be explained, study of this simple vertebrate has uncovered basic principles about the function and organization of vertebrate nervous systems.

Keywords: pattern generation, Xenopus, spinal interneurons, tonic inhibition, reflex

\section{INTRODUCTION}

We would all like to understand how our brain allows us to behave but we all know that the human brain is ridiculously complicated containing more than 2 billion nerve cells each of which can make thousands of connections at synapses. It is therefore no surprise that our understanding is remarkably poor: techniques like brain scanning allow us to determine which parts are responsible for perception of sounds, generation of speech, memory of where we live and our emotions but despite many decades of detailed study by thousands of neuroscientists we can't explain how nerve cell circuits allow us to do simple things like chew gum. The fundamental problem is the complexity and small scale of construction of nervous systems in all animals. One way to avoid the complexity of the nervous system of humans and other higher vertebrates is to investigate simpler animals which also have simpler behavior like: jellyfish but even here, nerve cells are very small (Mackie, 2004); leeches (Kristan et al., 2005); molluscs such as Clione (Arshavsky et al., 1993), Lymnea (Vavoulis et al., 2007), and Tritonia (Sakurai and Katz, 2003); crayfish (Edwards et al., 1999); and finally two animals where powerful genetic tools are available but neurons are very small making physiology either impossible or very difficult, the nematode Caenorhabdites where all the neurons are identified (Dittman, 2009) and the fly Drosophila (Crisp et al., 2008; Olsen and Wilson, 2008).

Another way to reduce complexity is to study animals at an early stage in their development. Our own studies on hatchling Xenopus tadpoles were inspired particularly by the apparent simplicity of the early amphibian nervous networks illustrated in a book "Anatomy and the problem of behavior" (Coghill, 1929). The critical feature that Coghill revealed was that the early vertebrate nervous system, while having a few thousand neurons like some invertebrates, was actually much simpler because it has a very restricted number of types of neuron. It is this feature of very young fish and amphibians which has allowed real progress in understanding how a whole nervous system generates behavior. Our review will outline this progress, focusing nearly exclusively on the hatchling Xenopus tadpole and beginning with an overview of the tadpole's behavior and nervous system organization. We therefore need to apologize immediately for the huge number of closely related studies that are not cited here.

\section{HATCHLING TADPOLE BEHAVIOR}

What behavior does the 5-mm long Xenopus tadpole have to enable it to survive when it hatches from the egg after 2 days? Like many other newly hatched tadpoles it spends $99 \%$ of its first day doing nothing, hanging from a strand of mucus secreted by the cement gland near where its mouth will form (Figure 1A; Jamieson and Roberts, 2000). Attachment to the water's surface is less secure than to solid objects. If they become detached, tadpoles sink, start to swim spontaneously, and in a small container, usually reattach within less than $10 \mathrm{~s}$. If a tadpole lying on the bottom of a dish is touched on the trunk or tail, it can simply flex weakly to the opposite side (Figure 1B) but in most cases it then swims off (Figures 1C-E) away from the side stimulated (Boothby and Roberts, 1995). The strength of the initial flexion is small when stimuli are on the tail 


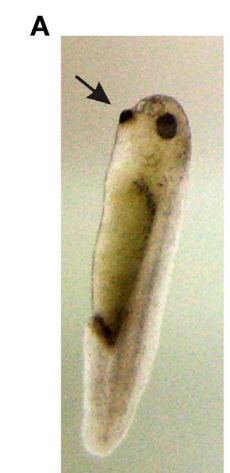

${ }^{\mathrm{B}}$ "

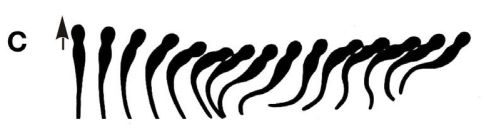

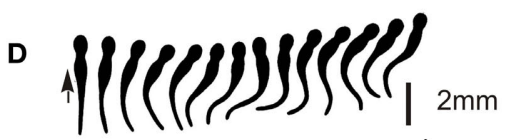

E

$\mathbf{F}$

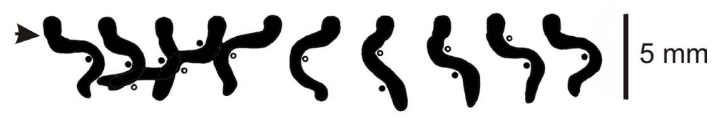

G

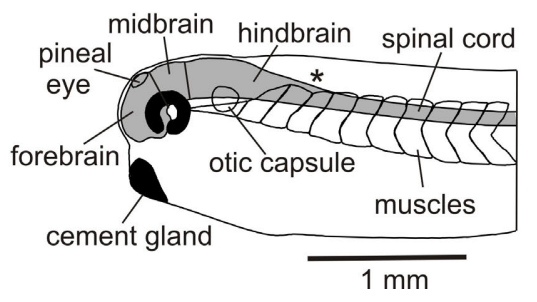

FIGURE 1 | Hatchling Xenopus tadpole and its behavior. (A) Stage 37/38 tadpole ( $5 \mathrm{~mm}$ long) at rest hanging by mucus from its cement gland (arrow) attached to the glass side of a tank. (B-E) Response to a short stroke with a hair (small arrow) seen from above in movies at $200 \mathrm{fps}$. (based on Boothby and Roberts, 1995) (B) Flexion (C-E) swimming (F) struggling when held at the neck (arrow). Points of maximum bending are shown by dots and circles, $64 \mathrm{fps}$. (based on Kahn and Roberts, 1982b). (G) Side view of the head end to show the main CNS regions.

and increases as stimuli are given more rostrally. Unlike newt tadpoles (Soffe et al., 1983) or larval zebrafish (Drapeau et al., 2002) which swim for only a few seconds, Xenopus tadpoles will swim for many seconds or even minutes if they don't bump into things (Kahn et al., 1982). Swimming frequencies usually lie between 10 and $25 \mathrm{~Hz}$. If an unattached tadpole is touched on the head, it makes a strong C-flexion to the same or the opposite side and then swims away in an unpredictable direction. Remarkably, it can swim the right way up (belly down), but this body orientation is achieved by ballast not reflex control (Roberts et al., 2000). Unattached tadpoles will also respond to sudden water currents by turning and swimming against the current (Roberts et al., 2009).

The hatched tadpole has lateral eyes but these do not seem to influence its behavior until a few days later. However, it also has a functional pineal eye (Roberts, 1978; Foster and Roberts, 1982) and if the light is dimmed while the tadpole is swimming, it speeds up and turns to swim vertically in a tight spiral (Jamieson and Roberts, 2000; Roberts et al., 2000). A very similar response has been seen in young cavefish larvae (Yoshizawa and Jeffery, 2008). In both animals, the spiral swimming brings them to the water's surface where they stop and attach. This stopping response and attachment is also seen when tadpoles swim head first into solid objects (Boothby and Roberts, 1992).
In temporary bodies of water with few fish, the main predators of very young tadpoles, apart from adults of their own species, are likely to be insects such as water scorpions and the larvae of beetles, damselflies and dragonflies (Lawler, 1989). If grasped by such larvae or held firmly with forceps, tadpoles make very strong bending movements which alternate at $2-5 \mathrm{~Hz}$, start at the tail, and progress towards the head. These struggling movements can free tadpoles so they are able to swim away (Figure 1F; Kahn and Roberts, 1982b).

\section{HATCHLING TADPOLE NERVOUS AND SENSORY SYSTEMS}

The CNS forms in the previous $24 \mathrm{~h}$ following the closure of the neural tube. It is still rapidly developing and can be divided into fore- mid- and hind-brain and spinal cord (Figure 1G). In the spinal cord, neuron somata form longitudinal columns with sensory Rohon-Beard (R-B) neurons along the dorsal midline and motoneurons ventro-laterally. Between these lie rather disorganized columns of interneurons. Neuron axons form a "marginal zone" outside the neuron somata and dendrites grow into this layer to receive "en-passant" synapses. A classification of spinal neurons, based on simple features like soma location, dendrite branching pattern, and axonal projection, suggested that there were just 8 types including two types of sensory neurons and one type of motoneuron (Roberts and Clarke, 1982; Roberts, 2000). This leaves just 5 anatomical types of interneuron which is remarkably few compared to the 28 types in a developing rat (Silos-Santiago and Snider, 1994) and probably even larger numbers of types in an invertebrate ventral nerve cord ganglion (eg insects; Burrows, 1996). More recent studies have shown that some of the basic anatomical types can be subdivided to give 10 types in total (see below). Rather unexpectedly, many columns of spinal neurons extend uninterrupted into the hindbrain in both Xenopus and zebrafish larvae. These columns are revealed by transmitter antibodies (Dale et al., 1986; Roberts et al., 1987) or the transcription factors the neurons express (Higashijima et al., 2004; Li et al., 2004a).

When it hatches, the tadpole is mainly sensitive to mechanical and light stimuli. The whole body surface is innervated by touch sensitive sensory neurons in the trigeminal ganglia and spinal cord (Roberts, 1980; Clarke et al., 1984). Other trigeminal sensory neurons which innervate the head skin and cement gland are excited by slow mechanical distortion pressure, for example when the tadpole bumps into objects while swimming (Roberts and Blight, 1975; Roberts, 1980). Curiously, amphibian tadpole skin is excitable (Wintrebert, 1904) and propagates an all-or-none, cardiac type action potential when strongly stimulated anywhere on the body (Roberts, 1969). This skin impulse can initiate swimming and is a primitive noxious stimulus detection system similar to those found in Cnidarians (Mackie, 1970). The tadpole also has lateral line neuromasts just caudal to the eyes (Schlosser and Northcutt, 2000) which allow tadpoles to respond to water currents by swimming into them (Roberts et al., 2009). Finally, tadpoles have a pineal eye excited by dimming (Foster and Roberts, 1982). This allows light to influence the swimming network in the hindbrain (Jamieson and Roberts, 1999). At the time they hatch little is known about early function of the nose in olfaction and physiological evidence is lacking to show that the inner ears, sense of balance and Mauthner neuron system are functional. However, Mauthner 
neurons are present (van Mier and ten Donkelaar, 1984) and it has been suggested that they can drive trunk flexions in young larvae (Sillar and Robertson, 2009).

\section{OVERVIEW}

At hatching, tadpoles can detect water currents, changes in light intensity and discriminate between touch, pressure and noxious skin stimuli, responding appropriately depending on strength and location. Although there are a few thousand functioning central neurons, these usually form populations of 20-150 on each side, so the task of uncovering their roles in behavior is not overwhelming.

\section{A SIMPLE REFLEX}

What are the features of the most basic vertebrate response pathways? Are the first reflexes as direct as possible, like the mammal knee jerk reflex where sensory afferent axons synapse with motoneurons? To study the neurons mediating the tadpole's responses, we have used whole-cell recording from pairs of neurons in tadpoles immobilized using the neuromuscular blocking agent $\alpha$-bungarotoxin (Li et al., 2002). Neuron somata can be seen using a 40× water immersion lens on a compound microscope after the CNS is exposed surgically and the spinal cord is opened by a dorsal longitudinal cut.

Nearly all animals respond to unpleasant or unexpected stimulation by flexing away from the stimulus. This type of withdrawal response is familiar from textbooks but in fact, the neurons mediating such basic reflexes had not previously been identified in any vertebrate. In the tadpole we already knew that RB neurons innervate the skin and respond to touch (Clarke et al., 1984). By recording from the motor nerves on each side of the body we showed that when a 1-ms current pulse to stimulate the RB nerve endings in the skin on one side is strong enough, the earliest response is a brief ventral root spike on the opposite side (Figure $2 \mathrm{~A}$ ). This would lead to a brief flexion, the reflex withdrawal and the neurons responsible were revealed by paired whole-cell recordings ( $\mathrm{Li}$ et al., 2003b). When sensory RB neurons are stimulated to fire an action potential, they produce strong, short excitation of sensory pathway dorsolateral commissural (dlc) interneurons at short and constant latencies which is often enough to make them fire an action potential (Figure 2B). This suggests direct, mono-synaptic connections and antagonist applications showed that this excitation was mainly AMPAR mediated. Since RB neurons have ascending and descending central axons, a single sensory neuron will excite many dlc interneurons to fire and the action potentials will be carried across the spinal cord ventrally by their commissural axons. Further paired recordings showed that dlc interneurons produce weak, long excitation of all contralateral neuron classes active during swimming, including motoneurons (Figure 2B). This weak excitation is mainly the result of NMDAR activation. As a result, considerable spatial and temporal summation is required for it to lead to postsynaptic neuron firing and a flexion on the other side. These recordings and the neuron morphologies revealed by neurobiotin filling have defined a simple three neuron reflex pathway from skin touch on one side to muscle contraction on the other. Even at this early stage of development, we find that the properties of synapses are tuned to suit their roles in the whole animal's responses.

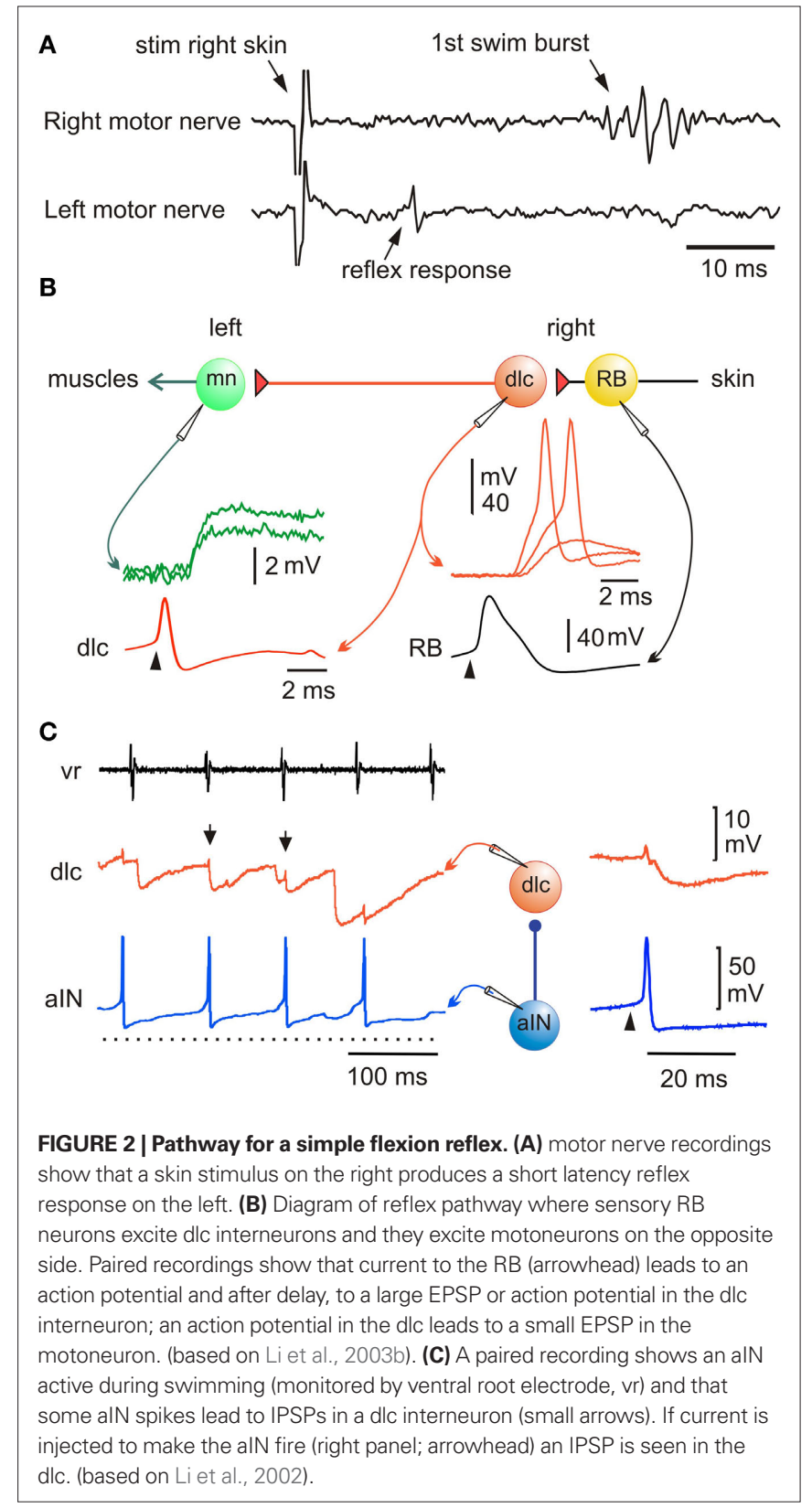

An early discovery about the sensory pathways was that responses to skin stimulation are gated out at a suitable phase of each swimming cycle by inhibition of the sensory pathway interneurons (Sillar and Roberts, 1988, 1992b). This inhibition prevents reflex responses from conflicting with swimming and impinges on the dlc interneurons and a second type of sensory pathway interneuron, dorsolateral ascending (dla) interneurons. These are also excited by RB sensory neurons, project axons directly up towards the brain on the same side and are probably involved in the initiation of swimming (Li et al., 2004b). Paired whole-cell recording showed that glycinergic inhibition of sensory pathway dlc interneurons during swimming comes from ascending interneurons (aINs; Figure 2C; Li et al., 2002). At present this is the only type of interneuron in Xenopus whose population can be defined because these neurons express the transcription factor engrailed, like their homologues in 
zebrafish larvae (Higashijima et al., 2004; Li et al., 2004a). Further, this is a rare case among vertebrates where the interneurons mediating sensory gating can be identified.

\section{OVERVIEW}

This investigation shows that the primitive reflex has two synapses so interneurons connect sensory neurons to motoneurons. These interneurons allow small sensory signals to be amplified and reflex responses to be controlled by inhibition. In this way reflexes are integrated with the whole animal's behavior. It is perhaps remarkable that such a subtle inhibitory mechanism should exist in the newly hatched tadpole but maybe phasic gating during swimming is less important than the strong inhibition of sensory pathway interneurons when swimming starts and aINs tend to fire more reliably. This broader inhibition could be important in allowing swimming to start uninterrupted by any reflex actions.

\section{SWIMMING}

The most obvious behavior of newly hatched fish and amphibians is swimming. Our investigation of the tadpole swimming network raises questions about the generally accepted hypothesis that spinal cord networks called central pattern generators, organized as half-centers, produce a rhythmic locomotor pattern if provided with steady, unpatterned excitation by the brain (Orlovsky et al., 1999). The fact that a swimming-like pattern of motor nerve activity alternating on the left and right and progressing from head to tail can occur in response to brief skin stimulation in immobilized fish and amphibian larvae shows that the basic swimming pattern can be generated without reflexes by the CNS (Kahn and Roberts, 1982a; Drapeau et al., 2002). Lesions in Xenopus tadpoles show that the basic pattern can still be generated for many seconds after a brief stimulus by a $0.3-\mathrm{mm}$ long region of caudal hindbrain and rostral spinal cord (Figure 3A; Li et al., 2006). This small region of CNS must therefore contain sufficient neurons and connections to generate a self-sustained basic swimming rhythm. On the other hand, the spinal cord alone can only generate a few cycles of rhythm following a skin stimulus. However, as in other decerebrated animals (Stein et al., 1997), if artificial excitation is provided by bath application of NMDA, then the spinal cord can organise long lasting swimming-like activity (Li et al., 2006). There are therefore two main things to explain: how does the nervous system sustain locomotor activity after it is initiated and, how is the pattern of motor output organized?

The main spinal neuron types, their activity during swimming and their synaptic connections have now been defined and proposals about how the spinal swimming circuits work tested using model networks (review Roberts, 1990). In the hatchling tadpole, though not at later stages (Sillar et al., 1991; McLean et al., 2000b), most spinal interneurons and motoneurons which are active during swimming: fire a single spike at a similar phase to motoneurons on each cycle, receive mid-cycle inhibition, and do not spike at rest (Figure 3B). The exception is ascending interneurons (aINs) which produce glycinergic recurrent inhibition to limit motoneuron firing and can fire more than once on each cycle (Li et al., 2004a). The glycinergic neurons producing mid-cycle reciprocal inhibition are commissural interneurons (cINs; Dale, 1985). Initially the identity of the excitatory descending interneurons (dINs)

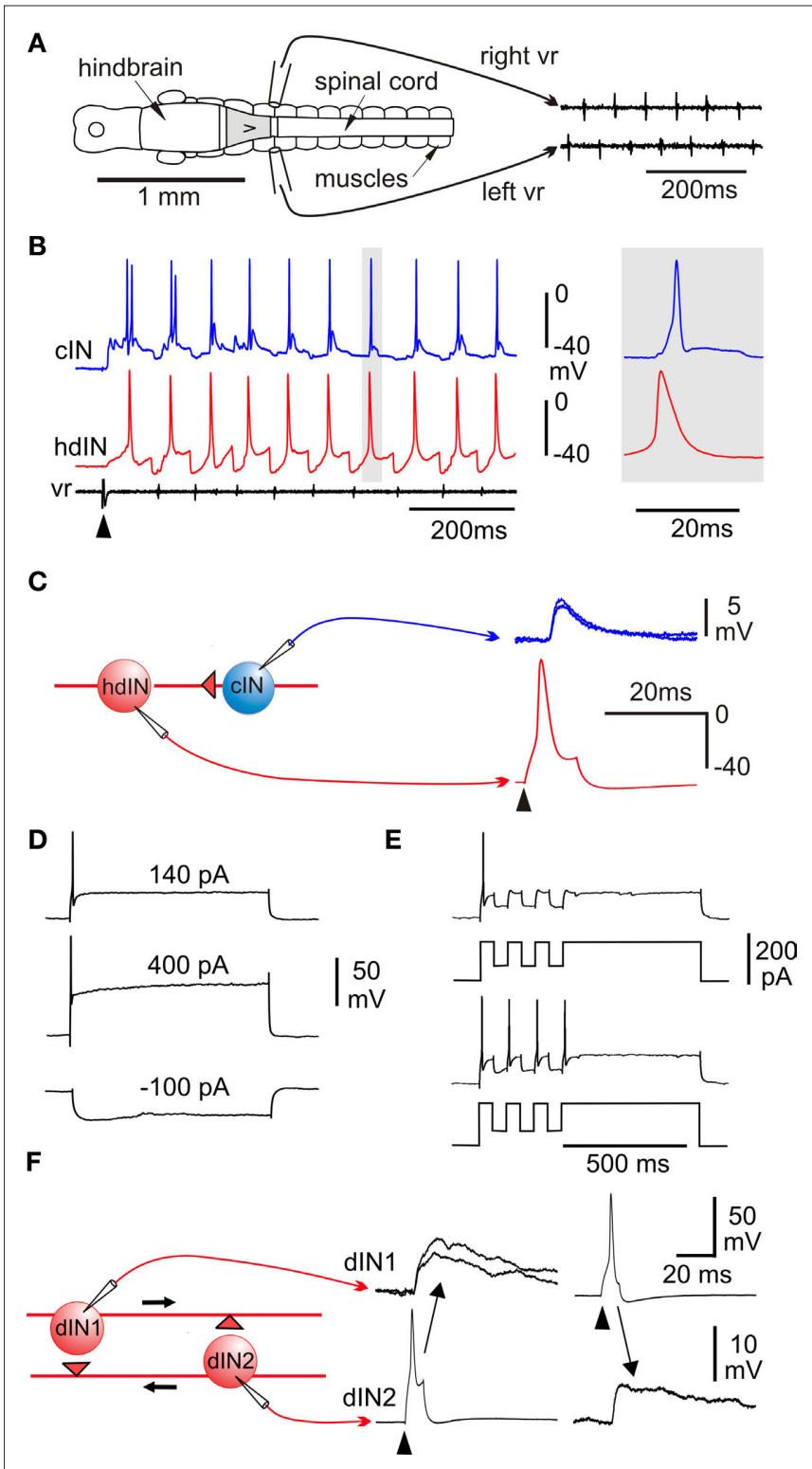

FIGURE 3 | Swimming: effects of lesions, activity patterns and excitation.

(A) CNS in dorsal view to show suction electrode positions to record alternating ventral root (vr) spikes during swimming generated by an isolated 0.3-mm long region of CNS (gray). (B) Whole-cell recording from a cIN and hindbrain dIN (hdIN) show both fire once on each cycle of swimming and the hdIN has a long action potential; (C) spike evoked in the hdIN by current (arrowhead) leads to an EPSP in the cIN. (D) A dIN fires once to positive current but does not fire on rebound after negative current. (E) If large enough, negative current pulses during depolarization can lead to postinhibitory rebound firing. (F) Recording from a pair of dINs in the hindbrain shows that when current is injected to make them fire (arrowheads) they produce long duration excitation in the other. (based on Li et al., 2006).

was rather uncertain but dramatically, they produced long duration glutamate excitation mediated by the activation of NMDA receptors (Dale and Roberts, 1985). In $0 \mathrm{Mg}^{2+}$ saline, this excitation could sum at swimming frequencies to produce an activity dependent tonic excitation. Sharp microelectrode recordings with marker filling also revealed that reticulospinal neurons, resembling 
dINs morphologically, were rhythmically active and fired once on each cycle of swimming (van Mier and ten Donkelaar, 1989). Recent whole-cell recording with neurobiotin injection to obtain anatomy has been most significant in confirming the role of dINs as the source of the excitatory drive for swimming locomotion (Li et al., 2006), something that has proven so difficult to track down in mammals (Kiehn, 2006). There is now direct evidence on the properties and connections of dINs. They have an unusually long-duration action potential compared to all other neurons active during swimming (Figure 3B) and usually only fire a single action potential to depolarizing current even well above threshold (Figure 3D). This contrasts with other spinal neurons which fire repetitively to injected current (eg Figure 6D). By recording from many pairs of connected neurons ample direct evidence is now available that dINs produce mainly fast excitation of cINs, aINs and mns (eg Figure 3C). Remarkably, they do this by coreleasing glutamate and acetylcholine which activates AMPA and nicotinic acetylcholine receptors ( $\mathrm{Li}$ et al., 2004c). Another discovery was also interesting. When dINs in the hindbrain were filled with neurobiotin, a much higher proportion had additional ascending axons and these allowed them to make reciprocal excitatory synapses (Figure 3F). At last we had direct evidence for the proposed NMDAR mediated feedback excitation (Dale and Roberts, 1985). The final important property of dINs is that they show post-inhibitory rebound firing to negative current pulses and IPSPs when they are depolarized (Figure 3E; Soffe et al., 2009) but IPSPs and negative current injection at rest rarely lead to delayed rebound firing as they do in the interneurons driving swimming in the marine mollusc Clione (Satterlie, 1985).

Detailed new evidence on the properties and connections of dINs in the hindbrain has finally given support to what was a tentative feedback excitation and post-inhibitory rebound hypothesis about rhythm generation. We propose that network activity is sustained by feedback of long duration glutamate excitation from dINs on each cycle of swimming. Very simple models show how this mechanism could work (Roberts and Tunstall, 1990). If the dIN is at rest, synaptic excitation can lead to firing but a cIN reciprocal inhibitory IPSP does not lead to rebound firing (Figure 4A1). Normally, when the dINs fire they feed longduration glutamate excitation back onto themselves. This holds them strongly depolarized but they do not fire again because they are very difficult to reexcite shortly after firing (Figure 4A2). If a cIN action potential produces a short IPSP in the dIN while it is still depolarized by the feedback excitation, it fires a delayed action potential on rebound from the inhibition (Figure 4A3). This would normally occur when dINs receive reciprocal inhibition from the opposite side. The critical features of dINs are: their single spike firing characteristics; the ability of long NMDAR mediated EPSPs to sum from cycle to cycle and hold dINs depolarized; their rebound after IPSPs from the other side when they are depolarized. We therefore incorporated these cellular and synaptic properties and connections into a minimal network model of the circuit in the hindbrain and rostral spinal cord which can generate long lasting swimming (Sautois et al., 2007). By adding a sensory activation pathway (with a sensory RB neuron and sensory pathway dlc and dla interneurons) we were able to show that the model could generate self-sustained swimming-like activity in response

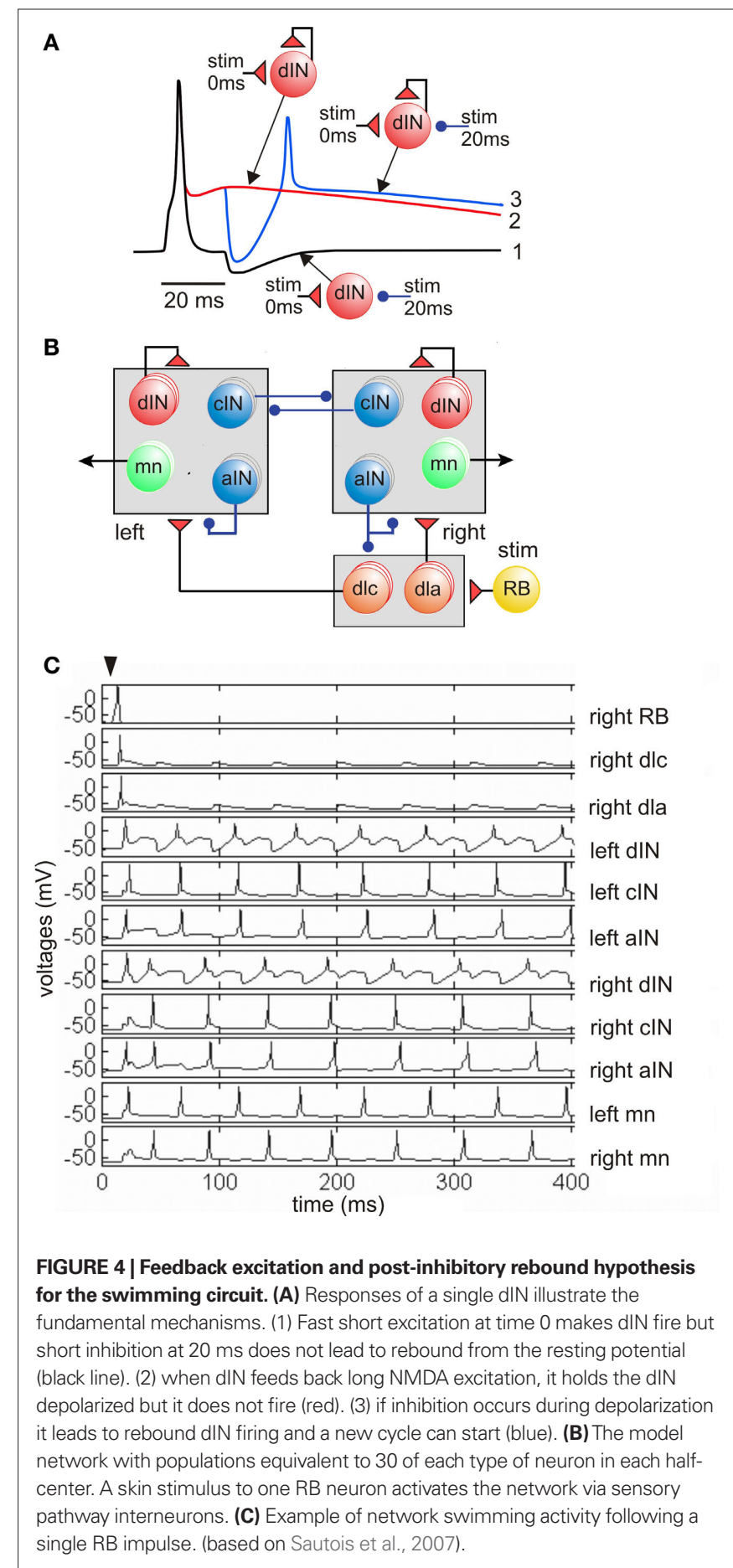

to a single impulse in the sensory RB neuron (Figures $4 \mathrm{~B}, \mathrm{C}$ ). In this network the first side to fire produces inhibition of the other side while it is still depolarized by the feedback excitation and it then fires on rebound from the reciprocal inhibition. An alternating rhythm of firing is established and sustains its activity indefinitely (in the model if not in life). This model shows that the basic principals can work but also shows that activity immediately following sensory stimulation is disorganized compared to the real nervous system. 
We have known for a long time that a single side of the Xenopus CNS can generate rhythm, even for a few cycles after inhibition is blocked (Soffe, 1989) so rhythmicity based on rebound from reciprocal inhibition cannot be the whole story (see also: Aiken et al., 2003; Dale, 2003). As in the swimming mollusc Clione and the mammal respiratory system (Arshavsky et al., 1993; Del Negro et al., 2002) it is therefore likely that multiple mechanisms contribute. For swimming in Xenopus, the dINs always seem to play a central role. There is evidence for NMDA induced pacemaker activity at swimming frequencies in unidentified spinal neurons of younger Xenopus embryos (Prime et al., 1999) and we have preliminary evidence that dINs express pacemaker properties within the swimming range when NMDARs are activated. Furthermore, dINs are electrically coupled and blocking this coupling pharmacologically with $18-\beta$ glycyrrhetinic acid can make their firing and the whole swimming rhythm generation less reliable ( $\mathrm{Li}$ et al., 2009). This experiment suggests that electrical connections between dINs contribute in some way to the stability of rhythm generation. Because we can identify and record from many dINs, we have been able to show that the members of the dIN population in the caudal hindbrain are the first neurons in the whole nervous system to fire on each cycle of swimming (Soffe et al., 2009). This evidence endorses our conclusion that it is the firing in these neurons which drives each cycle of swimming by providing fast, strong excitation of interneurons and motoneurons in the spinal cord. Since dINs in the hindbrain have axons which project into the spinal cord, most anatomists would classify them as reticulospinal neurons. So our suggestion in this case is that the primary role of excitatory reticulospinal neurons is to drive the swimming activity of spinal neurons phasically on a cycle-bycycle basis rather than simply to provide a steady tonic excitation to turn on rhythm generation in the spinal cord half-centers or pattern generators.

Further evidence sheds light on motoneuron connections and the way activity spreads from head to tail. In many rhythmic systems electrical coupling between neurons is thought to play an important role (Connors and Long, 2004). Paired recordings from ventral neurons presumed to be motoneurons, showed that neighboring ventral neurons $<150-\mu \mathrm{m}$ apart were electrically coupled (Perrins and Roberts, 1995) and model networks show that such coupling makes motoneurons fire more synchronously (Wolf et al., 2009; Zhang et al., 2009). Surprisingly, paired recordings from motoneurons also showed that they make central cholinergic chemical synapses with each other (Perrins and Roberts, 1995). To try to understand the significance of these synapses and how activity spreads from head to tail along the spinal cord during swimming, recordings were made from neurons at different longitudinal positions. Both the strength of mid-cycle inhibition and the level of steady (tonic) excitation immediately preceding it decreases from head to tail (Tunstall and Roberts, 1994; Zhao et al., 1998). Modeling of the swimming network shows that the longitudinal gradients in excitation, but not inhibition, can produce a head to tail progression of activity during swimming (Wolf et al., 2009). However, the interpretation of the cholinergic component of excitation is now more complex because dINs corelease glutamate and acetyl choline (Li et al., 2004c). We don't understand the significance of this finding but it means that we cannot assume that all spinal cholinergic excitation comes from motoneurons. Corelease of the inhibitory transmitters glycine and GABA has been found in other developing systems (Jonas et al., 1998) but, here too, the significance is unclear.

In immobilized tadpoles the swimming frequency normally drops slowly after initiation and the mechanisms for this and increased frequency following stimulation have been investigated. Since the neurons active in swimming usually fire a single spike per cycle, a drop in frequency is most simply explained by fewer neurons firing (Sillar and Roberts, 1993). Alternatively, synaptic strength could weaken or neurons could become less excitable. Direct evidence has shown that during swimming activity ATP is released in the CNS and is converted in the extracellular space to adenosine (Dale and Gilday, 1996; Dale, 2002). This depresses neuron excitability so can lead to a slowing of swimming frequency. On the other hand, if tadpoles are touched while swimming, the frequency goes up transiently (Sillar and Roberts, 1992a). Free moving tadpoles would undoubtedly turn following stimulation, but although we can see them make spontaneous turns during swimming and start swimming spontaneously from rest, we know little about how these responses arise in the CNS. On the other hand, we have information on how light dimming leads to an increase in swim frequency (Jamieson and Roberts, 2000). Extracellular recordings have shown that dimming excites pineal ganglion cells and that these in turn excite diencephalic-mesencephalic interneurons which fire tonically. These interneurons project to the hindbrain where they are presumed to excite the swimming network to drive light-evoked and maybe also spontaneous activity (Jamieson and Roberts, 1999).

\section{OVERVIEW}

Within the last decade and as a direct result of using whole-cell recording under visual guidance we have built up a detailed picture of the neurons in the swimming network, their anatomy, properties, connections and activities. This evidence has allowed us to construct a simple model of the minimal swimming network located in the caudal hindbrain and rostral spinal cord which will generate selfsustained "swimming" following a brief sensory stimulus (Figure 4; Sautois et al., 2007). We are confident that this model encapsulates the central principles of operation of this network where the dINs and reciprocal inhibition play a critical role. However, the picture is still far from complete: the mechanisms for rhythm generation within a single half CNS remain to be resolved; the lack of more incisive experimental methods to test hypotheses is frustrating; we still can only define the whole population of one type of neuron in the swim network (aINs); the pathway and mechanisms for the initiation of swimming are vague as is the origin of spontaneous swimming; the membrane currents underlying the different neuron firing properties are only beginning to be explored.

\section{INHIBITORY PATHWAYS TO CONTROL BEHAVIOR}

What are the mechanisms that allow animals to stop their locomotion when they reach their objective? Simple stopping responses are well known: a leech stops swimming when its front sucker contacts prey, a fly or locust stops flying when its feet touch the ground (Gray et al., 1938; Dingle, 1961). Similarly, swimming tadpoles stop when their head bumps into the water's surface or objects like vegetation and the side of a dish. When they are immobilized, motor nerve swimming activity stops when the head skin or cement gland is 
pressed slowly with a blunt probe. This has allowed us to trace the inhibitory pathways responsible for stopping and to make the surprising discovery that the same pathways are continually active when the tadpole hangs from its cement gland at rest, reducing its overall excitability. Recordings showed that the sensory neurons excited when the tadpole bumps into things, is pressed on the head skin or cement gland, or hangs from its mucus strand, lie in the trigeminal ganglia and project axons into the hindbrain (Roberts and Blight, 1975; Roberts, 1980).

The targets of the trigeminal sensory neurons are a population of GABAergic midhindbrain reticulospinal neurons (mhrs) (Roberts et al., 1987). These were revealed by sharp electrode recordings to be inhibited during swimming but excited by the slow mechanical stimulation of the head skin that stopped swimming (Figure 5B; Perrins et al., 2002). The most remarkable finding was that injection of current to make a single mhr fire repetitively could stop the whole swimming network (Figure 5C). Further recordings showed that mhrs receive glutamatergic excitation from cement

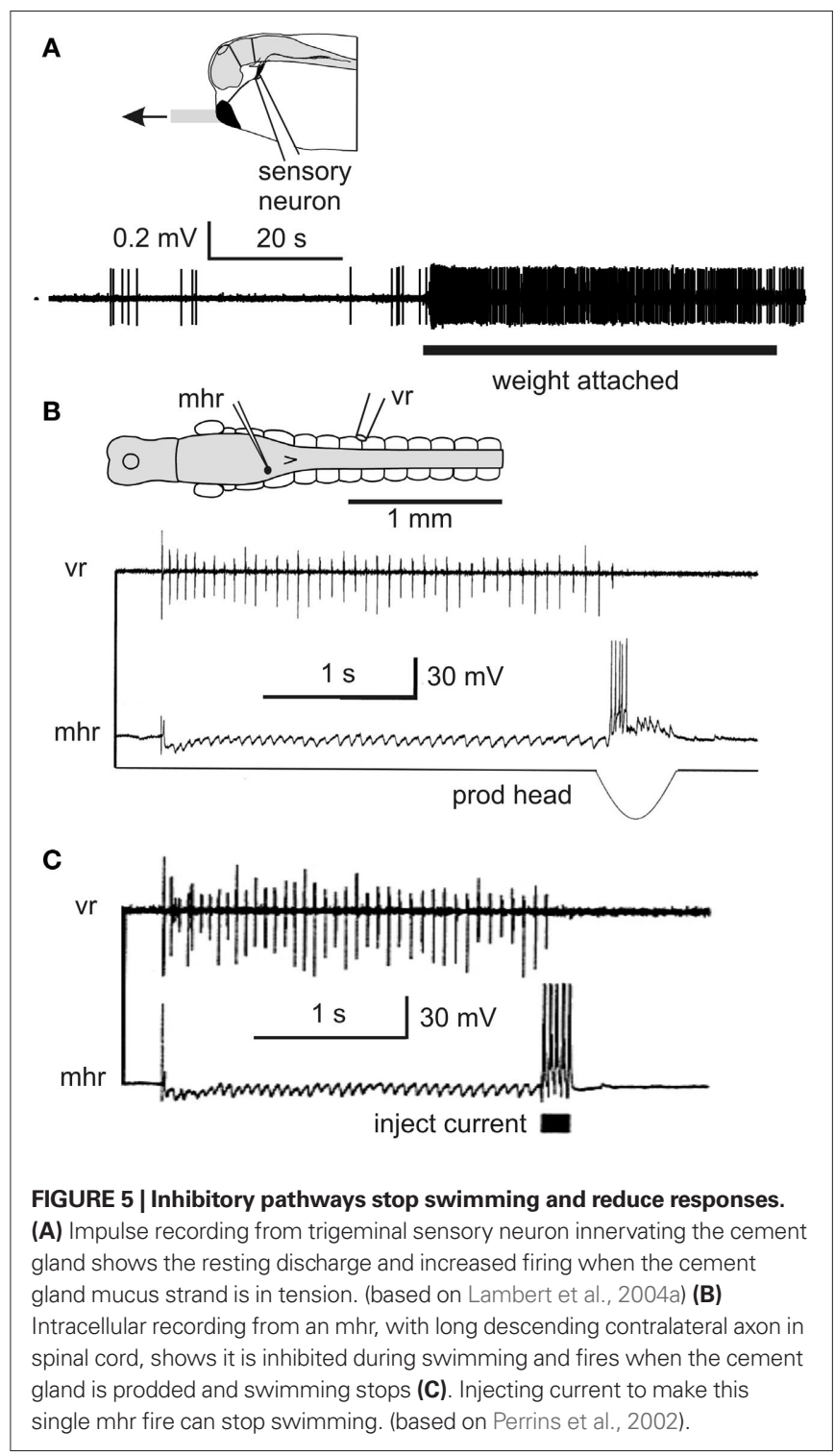

gland sensory neurons and produce GABA mediated inhibition of all spinal neurons active in swimming (Li et al., 2003a). These experiments define the neurons in the stopping pathway.

An intriguing discovery was that sensory neurons innervating the cement gland are continuously active at low levels $(\sim 1 \mathrm{~Hz})$ while the tadpole hangs from a mucus strand (Figure 5A; Lambert et al., 2004b)? What is the significance of this low level firing? Is it sufficient to excite the mhrs and produce tonic inhibition and so reduce responsiveness during attachment? Recordings of the spike activity of hindbrain neurons in the region where mhrs lie (6th-7th rhombomere) showed that they fired at very low rates without stimulation but their firing increased while a weight was attached to the cement gland mucus (mean $0.5 \pm 0.4 \mathrm{~Hz}$ ). Further rostral hindbrain neurons were found with increased firing during weight attachment. Using this evidence on hindbrain neurons and data on the number of sensory axons entering each side of the cement gland we modeled the summation of excitation in mhrs and concluded that it could be sufficient to lead to their low firing rates seen during attachment. We then made estimates of the inhibition that these low rates could produce in spinal neurons. Many assumptions are required but we suggested that the mhr firing we have recorded may lead to effective inhibition of spinal circuits for $60 \%$ of the time that the tadpole hangs from its mucus strand.

\section{OVERVIEW}

We have traced the pathway from trigeminal sensory neurons innervating the head skin and cement gland to hindbrain reticulospinal neurons (mhrs) producing GABA inhibition of spinal neurons. This inhibition stops swimming. When the tadpole hangs at rest from a strand of mucus secreted by its cement gland, the same pathway is active at very low rates. This produces continual low level inhibition which makes the tadpole less responsive and keeps it inactive. If these inhibitory pathways are disabled, tadpoles move more and more are eaten by predatory insects like the larvae of damselflies (Lambert et al., 2004a). Since the hatchling tadpole spends $98 \%$ of its time hanging from a mucus strand, continuous inhibition is a major feature of its nervous activity.

\section{STRUGGLING}

How does a simple neuronal network produce two motor output patterns? Many animals can use the same muscular system to produce different gaits, like walking, trotting and running. In the young tadpole we have already considered swimming to skin touch. Struggling is a slower, stronger series of rhythmic alternating trunk flexions seen while tadpoles are grasped by predators. How do two kinds of stimuli to the skin lead to different responses? Are the same or different neurons involved in both actions? Are the rhythm generation mechanisms the same or different?

In the immobilized tadpole the switch to struggling is dramatic. When the same single short current pulse to the skin which leads to swimming, is given repeatedly at $25-40 \mathrm{~Hz}$ the pattern changes to struggling and if the stimuli stop, the motor pattern switches back to swimming (Figures 6A,B; Soffe, 1991, 1993, 1997). Repetitive electrical skin stimulation can produce struggling even in spinal animals (Soffe, 1991). During struggling, active neurons fire bursts of spikes on each cycle at frequencies up to $245 \mathrm{~Hz}$ (Li et al., 2007) rather than the single spikes seen in swimming. Furthermore, the activity 


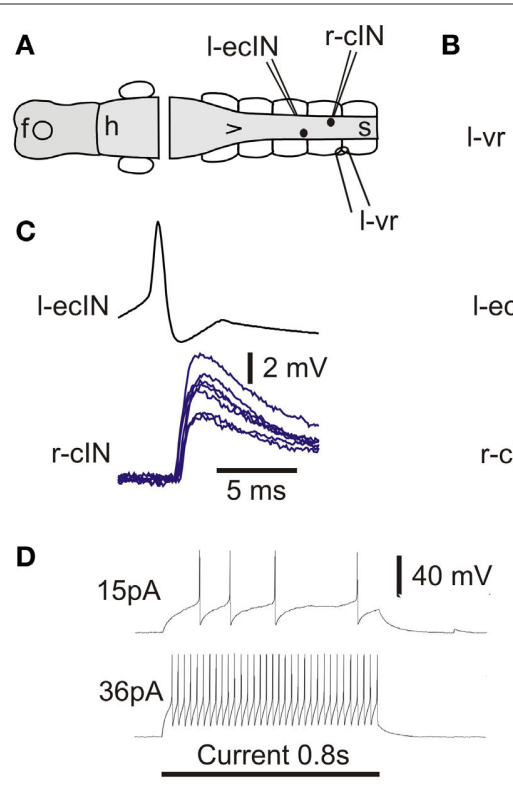

$\mathbf{F}$

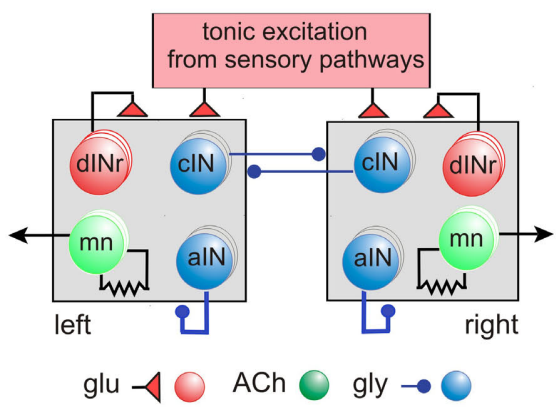

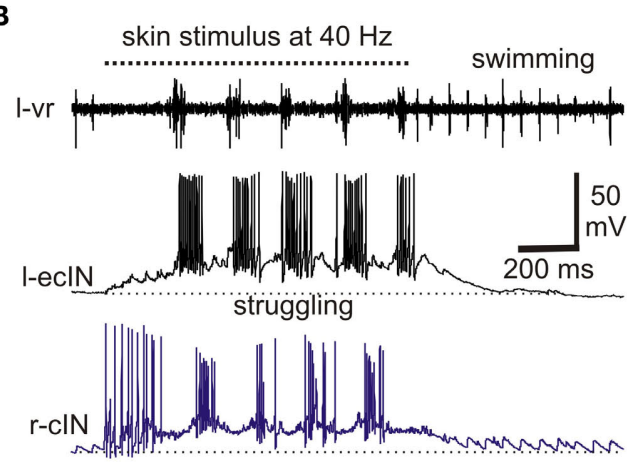

E

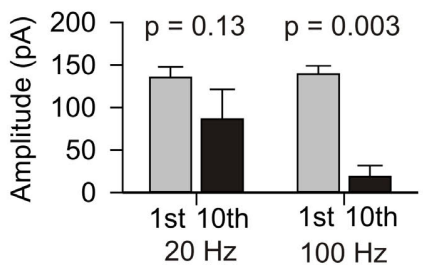

G

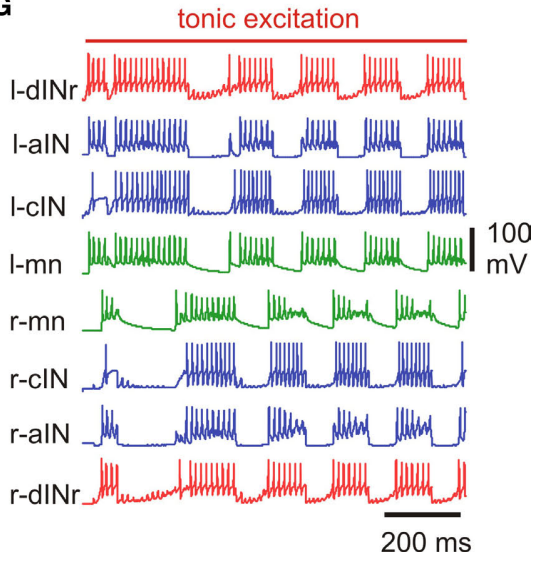

typical repetitive firing. (E) Measures of 1st and 10th compound IPSCs evoked in a dIN by stimulation of the opposite side show significant depression only with 100- $\mathrm{Hz}$ stimulation. (F) Half-center model of struggling network without length with three of each type of neuron on each side. (G) If cIN inhibition shows depression, this network can reliably generate struggling- like activity during tonic sensory excitation. (based on Li et al., 2007). spreads from tail to head, the opposite direction to swimming. Extra neurons are recruited during struggling including motoneurons, ascending and commissural interneurons whose populations also participate in swimming. When much more extensive recordings became possible using the whole-cell technique, the picture changed. Two previously undefined types of spinal neuron are also recruited during struggling ( $\mathrm{Li}$ et al., 2007). The first of these new types are excitatory commissural interneurons (ecINs; Figures 6B-D). They receive weak excitation during repetitive skin stimulation which sums slowly until they start to fire bursts in phase with motoneurons on the same side (Figure 6B). Paired recordings showed that ecINs produce glutamate mediated excitation of contralateral neurons and fire repetitively when current is injected (Figures 6C,D). Neurobiotin filling showed that they have a commissural axon like cINs but they often have more dorsal dendrites. The second type of neuron recruited was indistinguishable from dINs in morphology (except that they never had ascending axons). We call them dINrepetitive $(\mathrm{dINr})$ because like ecINs they fire repetitively when depolarizing current is injected. In addition, their action potential is significantly shorter in duration than the dINs. DINrs produce glutamate mediated excitation of neurons on the same side (mns, cINs, aINs and dINrs). The dINs which are so reliably active in swimming are inactive or very unreliable in struggling. We conclude that when the skin is continually stimulated, RBs are active and produce steady tonic excitation to drive ecINs, three types of premotor interneuron (dINrs, cINs and aINs) and motoneurons.

The next question was how the steady RB sensory excitation was converted into the struggling pattern of motor activity. Fortunately, Brown's hypothesis provides a possible mechanism (Brown, 1911, 1914) in contrast to the situation during swimming (see above). 
A critical element of this hypothesis is that reciprocal inhibition depresses with time allowing the inactive half-center to fire and turn off the first. In this way steady, tonic excitation is converted into an alternating pattern of activity. In the tadpole, the continuous stimulation of the sensory RB neurons provides tonic excitation of spinal and hindbrain neurons. This excitation can be direct or indirect, as in the case of contralateral neurons which are excited via the commissural axons of ecINs. Reciprocal inhibition comes from cINs. We therefore blocked synaptic excitation, recorded from a neuron on one side of the spinal cord and stimulated the other side to make cINs fire. This produced reciprocal inhibitory IPSCs in the recorded neuron (Li et al., 2007). When evoked at $100 \mathrm{~Hz}$ as in struggling, the IPSCs decreased in amplitude but there was no significant decrease if the stimulation frequency was in the swimming range ( $20 \mathrm{~Hz}$; Figure $6 \mathrm{E}$ ). To see if this decrease in inhibition was central to the production of the struggling motor pattern we built a simple model of the spinal circuit for struggling (Figure 6F). Since we knew that we did not properly understand the details of the sensory activation of this circuit, we simply provided all the neurons with tonic glutamate mediated excitation. Without the activity dependent depression of reciprocal inhibition, alternation in the model was unstable. However, if depression of reciprocal inhibition was introduced, the network had a large area of parameter space where stable struggling-like activity was generated (Figure 6G).

\section{OVERVIEW}

The decision to swim or struggle depends on the firing pattern of the same sensory RB neurons innervating the trunk skin: single or short bursts of action potentials lead to swimming; prolonged firing leads to struggling which only occurs during RB firing. Continuous head skin stimulation can also lead to struggling but the pathways have not been investigated. In contrast to swimming, the pathways activating struggling require summation of weak synaptic excitation. Most neurons active in swimming are also active in struggling but new neuron types are also recruited and the main excitatory interneurons that drive swimming (dINs) fire weakly if at all (see Berkowitz et al., 2010; (Frigon, 2009)). Struggling is driven by glutamate excitation and glycine inhibition. Neurons on one side releasing both transmitters all fire together but some project axons on the same side (dINrs and aINs) while others project to the opposite side (ecINs and cINs). This means that during struggling there is always a simultaneous mix of excitation and inhibition. The vigorous firing pattern must therefore depend on the balance between these opposing synaptic drives as has been proposed for control of turtle limb movements (Berg et al., 2007). The mechanisms controlling the tail to head spread of motor activity during struggling have not yet been explored. Perhaps the most significant findings are that struggling really does depend on tonic excitation coming from continual sensory input via RB neurons and that burst termination during struggling depends on the depression of reciprocal inhibition. We therefore have direct evidence for two parts of a hypothesis for locomotor rhythm generation first proposed in 1911 (Brown, 1911).

\section{FINAL COMMENT}

This review focuses on the roles of spinal neurons in generating the behavior of a very simple animal, the newly hatched Xenopus tadpole. Such an animal should help us to understand what the minimum sensory and nervous capabilities are required for survival. We now have partial explanations at the cellular level of how the main responses of the hatchling tadpole are generated. However, there are still many things we know about but can't explain: the details of the neuronal pathways responsible for the initiation of swimming and struggling; the cellular mechanisms for swimminglike rhythm generation within a single isolated half of the CNS; the neuronal origin of spontaneous swimming movements; the mechanisms for spontaneous turning during swimming; the neuronal pathways for turning and swimming responses to water currents detected by lateral line neuromasts; the modulatory roles of endogenously released serotonin (McLean et al., 2000a) and NO (McLean and Sillar, 2004); the natural stimuli exciting KolmerAgduhr cells with cilia in the spinal canal (Dale et al., 1987) and their normal function (but for larval zebrafish see (Wyart et al., 2009); the functions of most groups of neurons in brain. After a long period when progress was limited by the difficulties in making single neuron recordings, the whole-cell recording technique under visual control has transformed the situation and led to rapid advances in understanding. We have identified the main categories of spinal neuron by morphology and, with one exception (K-A cells), defined their properties and functions for one stage of development in Xenopus. At least some of the homologies between interneurons in fish and mammals are beginning to emerge (Frigon, 2009; Goulding, 2009) and we look forward to being able to find the transcription factors expressed by more of the Xenopus spinal interneurons. By identifying the excitatory interneurons that drive swimming and showing that their population extends into the hindbrain, we have been able to explore how the brain controls swimming locomotion. This work has uncovered major differences in the rhythm generating mechanisms in the two main types of rhythmic movement (swimming and struggling). Swimming activity is sustained on a cycle-by-cycle basis and depends on synaptic feedback from the activity within the pattern generating network itself. Struggling, on the other hand, depends on continuous tonic drive from outside the pattern generating circuits which, in this case, comes from continuous sensory stimulation. However, the way the spinal circuits convert continuous tonic excitation into a rhythmic motor pattern has provided clear evidence in favor of Brown's hypothesis for rhythm generation (Brown, 1914) which still underpins much work on adult locomotor rhythm generation. We discuss the networks generating different tadpole movement gaits elsewhere (Berkowitz, Roberts and Soffe, 2010) and show that they share some interneurons but not others. Finally, a real surprise was the discovery that tonic inhibition is occurring for $98 \%$ of the time during the tadpole's first day after hatching. This tonic GABA mediated inhibition reduces responsiveness and helps to keep the tadpole still so it does not attract the attention of visual predators like insect larvae. It will be very interesting to see if other animals, both simple and more advanced use such tonic inhibition in what seems to be a very uneconomic way.

\section{ACKNOWLEDGMENTS}

We thank Drs Edgar Buhl and Debbie Conte for helpful comments on drafts of this review and the Wellcome Trust who supported much of the work reported here. Wen-Chang Li thanks the Royal Society for direct support. 


\section{REFERENCES}

Aiken, S. P., Kuenzi, F. M., and Dale, N. (2003). Xenopus embryonic spinal neurons recorded in situ with patchclamp electrodes-conditional oscillators after all? Eur. J. Neurosci. 18, 333-343.

Arshavsky, Y., Orlovsky, G. N., Panchin, Y. V., Roberts, A., and Soffe, S. R. (1993). Neuronal control of swimming locomotion: analysis of the pteropod mollusc Clione and embryos of the amphibian Xenopus. Trends Neurosci. $16,227-233$

Berg, R.W.,Alaburda,A., and Hounsgaard, J. (2007). Balanced inhibition and excitation drive spike activity in spinal half-centers. Science 315, 390-393.

Berkowitz, A., Roberts, A., and Soffe, S. R. (2010). Roles for multifunctional and specialized spinal interneurons during motor pattern generation in tadpoles, zebrafish larvae, and turtles. Front. Behav. Neurosci. 4:36. doi: 10.3389/fnbeh.2010.00036

Boothby, K. M., and Roberts, A. (1992). The stopping response of Xenopus laevis embryos: pharmacology and intracellular physiology of rhythmic spinal neurones and hindbrain neurones. J. Exp. Biol. 169, 65-86.

Boothby, K. M., and Roberts, A. (1995). Effects of site and strength of tactile stimulation on the swimming responses of Xenopus laevis embryos. J. Zool. (Lond.) 235, 113-125.

Brown, T. G. (1911). The intrinsic factor in the act of progression of the mammal. Proc. R. Soc. Lond., B, Biol. Sci. 84, 308-319.

Brown, T. G. (1914). On the nature of the fundamental activity of the nervous centres; together with an analysis of the conditioning of rhythmic activity in progression, and a theory of the evolution of function in the nervous system. J. Physiol. (Lond.) $48,18-46$.

Burrows, M. (1996). The Neurobiology of an Insect Brain. Oxford: Oxford University Press.

Clarke, J. D. W., Hayes, B. P., Hunt, S. P., and Roberts, A. (1984). Sensory physiology, anatomy and immunohistochemistry of Rohon-Beard neurones in embryos of Xenopus laevis. J. Physiol. (Lond.) 348, 511-525.

Coghill, G. E. (1929). Anatomy and the Problem of Behaviour. London: Cambridge University Press.

Connors, B. W., and Long, M. A. (2004). Electrical synapses in the mammalian brain. Annu. Rev. Neurosci. 27, 393-418.

Crisp, S., Evers, J. F., Fiala, A., and Bate, M. (2008). The development of motor coordination in Drosophila embryos. Development 135, 3707-3717.
Dale, N. (1985). Reciprocal inhibitory interneurones in the Xenopus embryo spinal cord. J. Physiol. (lond.) 363, 61-70.

Dale, N. (2002). Resetting intrinsic purinergic modulation of neural activity: an associative mechanism? J. Neurosci. 22, 10461-10469.

Dale, N. (2003). Coordinated motor activity in simulated spinal networks emerges from simple biologically plausible rules of connectivity. J. Comput. Neurosci. 14, 55-70.

Dale, N., and Gilday, D. (1996). Regulation of rhythmic movements by purinergic neurotransmitters in frog embryos. Nature 383, 259-263.

Dale, N., Ottersen, O. P., Roberts, A., and Storm-Mathisen, J. (1986). Inhibitory neurones of a motor pattern generator in Xenopus revealed by antibodies to glycine. Nature 324, 255-257.

Dale, N., and Roberts, A. (1985). Dual component amino - acid - mediated synaptic potentials: excitatory drive for swimming in Xenopus embryos. J. Physiol. (Lond.) 363, 35-59.

Dale, N., Roberts, A., Ottersen, O. P., and Storm_Mathisen, J. (1987). The morphology and distribution of "Kolmer-Agduhr cells," a class of cerebrospinal-fluid-contacting neurons revealed in the frog embryo spinal cord by GABA immunocytochemistry. Proc. R. Soc. Lond., B, Biol. Sci. 232, 193-203.

Del Negro, C. A., Morgado-Valle, C., and Feldman, J. L. (2002). Respiratory rhythm: an emergent network property? Neuron 34,821 .

Dingle, H. (1961). Fight and swimming in giant water bugs. Biol. Bull. Mar. biol. Lab. 121, 117-128.

Dittman, J. (2009). "Chapter 2 worm watching: imaging nervous system structure and function in Caenorhabditis elegans," in Advances in Genetics, Vol. 65, ed. F. G. Stephen (New York: Academic Press), 39-78.

Drapeau, P., Saint-Amant, L., Buss, R. R., Chong, M., McDearmid, J. R., and Brustein, E. (2002). Development of the locomotor network in zebrafish. Prog. Neurobiol. 68, 85-111.

Edwards, D. H., Heitler, W. J., and Krasne, F. B. (1999). Fifty years of the command neuron: the neurobiology of escape behavior in the crayfish. Trends Neurosci. 22, 153-161.

Foster, R. G., and Roberts, A. (1982). The pineal eye in Xenopus laevis embryos and larvae: a photoreceptor with a direct excitatory effect on behaviour. J. Comp. Physiol. 145, 413-419.

Frigon, A. (2009). Reconfiguration of the spinal interneuronal network during locomotion in vertebrates. $J$. Neurophysiol. 101, 2201-2203.
Goulding, M. (2009). Circuits controlling vertebrate locomotion: moving in a new direction. Nat. Rev. Neurosci. 10, 507-518.

Gray, J., Lissmann, H. W., and Pumphrey, R. J. (1938). The mechanism of locomotion in the leech (Hirudo medicinalis). J. Exp. Biol. 15, 408-430.

Higashijima, S., Masino, M. A., Mandel, G., and Fetcho, J. R. (2004). Engrailed1 expression marks a primitive class of inhibitory spinal interneuron. $J$. Neurosci. 24, 5827-5839.

Jamieson, D., and Roberts, A. (1999). A possible pathway connecting the photosensitive pineal eye to the swimming central pattern generator in young Xenopus laevis tadpoles. Brain Behav. Evol. 54, 323-337.

Jamieson, D., and Roberts, A. (2000) Responses of young Xenopus laevis tadpoles to light dimming: possible roles for the pineal eye. J. Exp. Biol. 203(Pt 12), 1857-1867.

Jonas, P., Bischofberger, J., and Sandkuhler, J. (1998). Corelease of two fast neurotransmitters at a central synapse. Science 281, 419-424.

Kahn, J. A., and Roberts, A. (1982a). The central nervous origin of the swimming motor pattern in embryos of Xenopus laevis. J. Exp. Biol. 99, 185-196.

Kahn, J. A., and Roberts, A. (1982b). The neuromuscular basis of rhythmic struggling movements in embryos of Xenopus laevis. J. Exp. Biol. 99, 197-205.

Kahn, J. A., Roberts, A., and Kashin, S. M. (1982). The neuromuscular basis of swimming movements in embryos of the amphibian Xenopus laevis. J. Exp. Biol. 99, 175-184.

Kiehn, O. (2006). Locomotor circuits in the mammalian spinal cord. Ann. Rev. Neurosci. 29, 279-306.

Kristan, J. W. B., Calabrese, R. L., and Friesen, W. O. (2005). Neuronal control of leech behavior. Prog. Neurobiol. $76,279$.

Lambert, T. D., Howard, J., Plant, A., Soffe, S., and Roberts,A. (2004a). Mechanisms and significance of reduced activity and responsiveness in resting frog tadpoles. J. Exp. Biol. 207, 1113-1125.

Lambert, T. D., Li, W. C., Soffe, S. R. and Roberts, A. (2004b). Brainstem control of activity and responsiveness in resting frog tadpoles: tonic inhibition. J. Comp. Physiol. A Neuroethol. Sens. Neural. Behav. Physiol. 190 331-342.

Lawler, S. P. (1989). Behavioural responses to predators and predation risk in four species of larval anurans. Anim. Behav. 38, 1039-1047.

Li, W.-C., Higashijima, S., Parry, D. M., Roberts, A., and Soffe, S. R. (2004a).
Primitive roles for inhibitory interneurons in developing frog spinal cord. $J$. Neurosci. 24, 5840-5848.

Li, W.-C., Perrins, R., Walford, A., and Roberts, A. (2003a). The neuronal targets for GABAergic reticulospinal inhibition that stops swimming in hatchling frog tadpoles. 189, 29-37.

Li, W.-C., Sautois, B., Roberts, A., and Soffe, S. R. (2007). Reconfiguration of a vertebrate motor network: specific neuron recruitment and context-dependent synaptic plasticity. $J$. Neurosci. 27, 12267-12276.

Li, W.-C., Soffe, S. R., and Roberts, A. (2004b). Dorsal spinal interneurons forming a primitive, cutaneous sensory pathway. J. Neurophysiol. 92, 895-904.

Li, W.-C., Soffe, S. R., and Roberts, A. (2004c). Glutamate and acetylcholine corelease at developing synapses. Proc. Natl. Acad. Sci. U.S.A. 101, 15488-15493.

Li, W.-C., Soffe, S. R., and Roberts, A. (2003b). The spinal interneurons and properties of glutamatergic synapses in a primitive vertebrate cutaneous flexion reflex. J. Neurosci. 23, 9068-9077.

Li, W.-C., Roberts, A., and Soffe, S. R. (2009). Locomotor rhythm maintenance: electrical coupling among premotor excitatory interneurons in the brainstem and spinal cord of young Xenopus tadpoles. J. Physiol. (Lond.) 587, 1677-1693.

Li, W.-C., Soffe, S. R., and Roberts, A. (2002). Spinal inhibitory neurons that modulate cutaneous sensory pathways during locomotion in a simple vertebrate. J. Neurosci. 22, 10924-10934.

Li,W.-C., Soffe, S. R., Wolf, E., and Roberts, A. (2006). Persistent Responses to brief stimuli: feedback excitation among brainstem neurons. J. Neurosci. 26, 4026-4035.

Mackie, G. O. (1970). Neuroid conduction and the evolution of conducting tissues. Q. Rev. Biol. 45, 319-332.

Mackie, G. O. (2004). Central neural circuitry in the jellyfish Aglantha: a model 'simple nervous system'. Neurosignals 13, 5-19.

McLean, D., Merrywest, S., and Sillar, K. (2000a). The development of neuromodulatory systems and the maturation of motor patterns in amphibian tadpoles. Brain Res. Bull. 53, 595-603.

McLean, D. L., Merrywest, S. D., and Sillar, K. T. (2000b). The development of neuromodulatory systems and the maturation of motor patterns in amphibian tadpoles.. Brain Res. Bull. 53, 595-603.

McLean, D. L., and Sillar, K. T. (2004). Metamodulation of a spinal locomotor network by nitric oxide. J. Neurosci. 24, 9561-9571. 
Olsen, S. R., and Wilson, R. I. (2008). Cracking neural circuits in a tiny brain: new approaches for understanding the neural circuitry of Drosophila. Trends Neurosci. 31, 512-520.

Orlovsky, G. N., Deliagina, T. G., and Grillner, S. (1999). Neuronal Control of Locomotion. Oxford: Oxford University Press

Perrins, R., and Roberts, A. (1995). Cholinergic and electrical synapses between synergistic spinal motoneurones in the Xenopus laevis embryo. J. Physiol. (Lond.) 485(Pt 1), 135-144.

Perrins, R., Walford, A., and Roberts, A. (2002). Sensory activation and role of inhibitory reticulospinal neurons that stop swimming in hatchling frog tadpoles. J. Neurosci. 22, 4229-4240.

Prime, L., Pichon, Y., and Moore, L. E. (1999). N-Methyl-D-aspartateinduced oscillations in whole cell clamped neurons from the isolated spinal cord of Xenopus laevis embryos. J. Neurophysiol. 82, 1069-1073.

Roberts, A. (1969). Conducted impulses in the skin of young tadpoles. Nature 222, 1265-1266.

Roberts, A. (1978). Pineal eye and behaviour in Xenopus tadpoles. Nature 273, 774-775.

Roberts, A. (1980). The function and role of two types of mechanoreceptive 'free' nerve endings in the head skin of amphibian embryos. J. Comp. Physiol. A 135, 341-348.

Roberts, A. (1990). How does a nervous system produce behaviour? A case study in neurobiology. Sci. Prog. 74, 31-51.

Roberts, A. (2000). Early functional organization of spinal neurons in developing lower vertebrates. Brain Res. Bull. 53, 585-593.

Roberts, A., and Blight, A. R. (1975). Anatomy, physiology and behavioural role of sensory nerve endings in the cement gland of embryonic Xenopus. Proc. R. Soc. Lond., B, Biol. Sci. 192, 111-127.

Roberts, A., and Clarke, J. D. W. (1982). The neuroanatomy of an amphibian embryo spinal cord. Proc. R. Soc. Lond. B 296, 195-212.

Roberts, A., Dale, N., Ottersen, O. P., and Storm-Mathisen, J. (1987). The early development of neurons with GABA immunoreactivity in the CNS of Xenopus laevis embryos. J. Comp. Neurol. 261, 435-449.

Roberts, A., Feetham, B., Pajak, M., and Teare, T. (2009). Responses of hatchling Xenopus tadpoles to water currents: first function of lateral line receptors without cupulae. J. Exp. Biol. 212, 914-921.

Roberts, A., Hill, N. A., and Hicks, R. (2000). Simple mechanisms organise orientation of escape swimming in embryos and hatchling tadpoles of Xenopus laevis. J. Exp. Biol. 203, 1869-1885.

Roberts, A., and Tunstall, M. J. (1990). Mutual re-excitation with post-inhibitory rebound: a simulation study on the mechanisms for locomotor rhythm generation in the spinal cord of Xenopus embryos. Eur. J. Neurosci. 2, 11-23.

Sakurai, A., and Katz, P. S. (2003). Spike timing-dependent serotonergic neuromodulation of synaptic strength intrinsic to a central pattern generator circuit. J. Neurosci. 23, 10745-10755.

Satterlie, R. A. (1985). Reciprocal inhibition and postinhibitory rebound produce reverberation in a locomotor pattern generator. Science 229, 402-404.

Sautois, B., Soffe, S. R., Li, W.-C., and Roberts, A. (2007). Role of type-specific neuron properties in a spinal cord motor network. J. Comp. Neurosci. 23, 59-77.

Schlosser, G. R., and Northcutt, G. (2000). Development of neurogenic placodes in Xenopus laevis. J. Comp. Neurol.418, 121-146.

Sillar, K. T., and Roberts, A. (1988). A neuronal mechanism for sensory gating during locomotion in a vertebrate. Nature 331, 262-265.

Sillar, K. T., and Roberts, A. (1992a). The role of premotor interneurons in phase-dependent modulation of a cutaneous reflex during swimming in Xenopus laevis embryos. J. Neurosci. 12, 1647-1657.

Sillar, K. T., and Roberts, A. (1992b). The role of premotor interneurons in phase-dependent modulation of a cutaneous reflex during swimming in Xenopus laevis embryos. J. Neurosci. 12, 1647-1657.

Sillar, K. T., and Roberts, A. (1993). Control of frequency during swimming in Xenopus embryos: a study on interneuronal recruitment in a spinal rhythm generator. J. Physiol. (Lond.) 472, 557-572.

Sillar, K. T., and Robertson, R. M. (2009). Thermal activation of escape swimming in post-hatching Xenopus laevis frog larvae. J. Exp. Biol. 212, 2356-2364.

Sillar, K. T., Wedderburn, J. F., and Simmers, A. J. (1991). The development of swimming rhythmicity in post-embryonic Xenopus laevis. Proc. R. Soc. Lond., B, Biol. Sci. 246 147-153.

Silos-Santiago, I., and Snider, W. D. (1994) Development of interneurons with ipsilateral projections in embryonic rat spinal cord. J. Comp. Neurol. 342, 221-231.

Soffe, S. R. (1989). Roles of glycinergic inhibition and N-methyl-D-aspartate receptor mediated excitation in the locomotor rhythmicity of one half of the Xenopus embryo central nervous system. Eur. J. Neurosci. 1, 561-571.

Soffe, S. R. (1991). Triggering and gating of motor responses by sensory stimulation: behavioural selection in Xenopus embryos. Proc. R. Soc. Lond., B, Biol. Sci. 246, 197-203.

Soffe, S. R. (1993). Two distinct rhythmic motor patterns are driven by common premotor and motor neurons in a simple vertebrate spinal cord. J. Neurosci. 13, 4456-4469.

Soffe, S. R. (1997). The pattern of sensory discharge can determine the motor response in young Xenopus tadpoles. J. Comp. Physiol. A 180, 711-715.

Soffe, S. R., Clarke, J. D. W., and Roberts, A. (1983). Swimming and other centrally generated motor patterns in newt embryos. J. Comp. Physiol. A 152, 535-544.

Soffe, S. R., Roberts, A., and Li, W.-C. (2009). Defining the excitatory neurons that drive the locomotor rhythm in a simple vertebrate: insights into the origin of reticulospinal control. $J$. Physiol. (Lond.) 587, 4829-4844.

Stein, P. S. G., Grillner, S., Selverston, A. I. and Stuart,D. G. (eds) (1997).Neurons, Networks, and Motor Behavior. Cambridge, Mass: MIT Press.

Tunstall, M. J., and Roberts, A. (1994) A longitudinal gradient of synaptic drive in the spinal cord of Xenopus embryos and its role in co-ordination of swimming. J. Physiol. (Lond.) 474, 393-405.

van Mier, P., and ten Donkelaar, H. (1989). Structural and functional properties of reticulospinal neurons in the earlyswimming stage Xenopus embryo. J. Neurosci. 9, 25-37.

van Mier, P. A., and ten Donkelaar, H. J. (1984). Early development of descending pathways from the brain stem to the spinal cord in Xenopus laevis as revealed by anterograde labelling. Anat. Embryol. 170, 295-306.

Vavoulis, D. V., Straub, V. A., Kemenes, I., Kemenes, G., Feng, J., and Benjamin, P. R. (2007). Dynamic control of a central pattern generator circuit: a computational model of the snail feeding network. Eur. J. Neurosci. 25, 2805-2818.

Wintrebert,P.(1904).Surl"existance d'une irritabilite excito-motrice primitive independante de voies nerveuse chez les embryons cilieas des batraciens. $C$. R. Soc. Biol. (Paris) 57, 645-647.

Wolf, E., Soffe, S., and Roberts, A. (2009). Longitudinal neuronal organization and coordination in a simple vertebrate: a continuous, semi-quantitative computer model of the central pattern generator for swimming in young frog tadpoles. J. Comput. Neurosci. 27, 291-308.

Wyart, C., Bene, F. D., Warp, E., Scott, E. K., Trauner, D., Baier, H., and Isacoff, E.Y. (2009). Optogenetic dissection of a behavioural module in the vertebrate spinal cord. Nature 461, 407-410.

Yoshizawa, M., and Jeffery, W. R. (2008). Shadow response in the blind cavefish Astyanax reveals conservation of a functional pineal eye. J. Exp. Biol. 211, 292-299.

Zhang, H.-Y., Li, W.-C., Heitler, W. J., and Sillar, K. T. (2009). Electrical coupling synchronises spinal motorneuron activity during swimming in hatchling Xenopus tadpoles. J. Physiol. (Lond.) 567, 4455-4466.

Zhao, F.Y., Wolf,E., and Roberts,A. (1998). Longitudinal distribution of components of excitatory synaptic input to motoneurones during swimming in young Xenopus tadpoles: experiments with antagonists. J. Physiol. (Lond.) 511(Pt 3), 887-901.

Conflict of Interest Statement: The authors declare that the research was conducted in the absence of any commercial or financial relationships that could be construed as a potential conflict of interest.

Received: 02 March 2010; paper pending published: 16 March 2010; accepted: 26 March 2010; published online: 24 June 2010.

Citation: Roberts A, Li W-C and Soffe SR (2010) How neurons generate behavior in a hatchling amphibian tadpole: an outline. Front. Behav. Neurosci. 4:16. doi: 10.3389/fnbeh.2010.00016

Copyright (c) 2010 Roberts, Li and Soffe. This is an open-access article subject to an exclusive license agreement between the authors and the Frontiers Research Foundation, which permits unrestricted use, distribution, and reproduction in any medium, provided the original authors and source are credited. 